\title{
Does exposure to environmental tobacco smoke increase the risk of lung cancer in smokers?
}

Environmental tobacco smoke (ETS) is well established as
a cause of numerous adverse health conditions, including
lung cancer, among adult non-smokers and as a cause of
respiratory conditions such as asthma and middle ear
infections among children. ${ }^{1}$ The 1992 report of the US
Environmental Protection Agency, ${ }^{1}$ which classified ETS
as a known human carcinogen, provided a new political
and legal context for regulation of ETS in the workplace. ${ }^{2}$
The opportunities for increased control of ETS exposure
include local tobacco control ordinances and financial
incentives for individual employers to avoid workers
compensation claims.
- ${ }^{2}$
antil now, ETS regulation has focused on protecting
adult non-smokers and children from the harmful health
effects of ETS exposure. The notion of protecting smokers
from the harmful effects of ETS has not been a prominent
part of the public health discourse. In this issue of Tobacco
Control, however, Siegel and his colleagues ${ }^{3}$ describe a
provocative analysis of the possible lung cancer risk among
smokers who are exposed to environmental tobacco smoke
in smoking lounges.

In their analysis, Siegel et al constructed a series of models to estimate the risk of lung cancer mortality related to workplace exposure among smokers who use a separately ventilated smoking lounge compared with those covered by a smoke-free policy. Their study used published and unpublished data on lung cancer risk in non-smokers and smokers in relation to ETS exposure and on average levels of nicotine in office workplaces and smoking lounges.

- Relying on published meta-analyses, they estimated a range of relative risks from 1.2 to 1.4 for lung cancer in non-smokers who are exposed to ETS. The authors calculated a pooled risk estimate of 1.3 for lung cancer in smokers exposed to ETS, and used this value as the upper bound in modelling. Nicotine was appropriately used as a marker for ETS exposure. Based on workplace data, nicotine exposure was estimated for workplaces that do not restrict smoking or that provide separately ventilated smoking areas. Modelling under a range of assumptions for the variables noted above, Siegel et al estimated deaths among smokers caused by ETS exposure in smoking lounges and found an upper range of 156000 excess lung cancer deaths over the next 45 years. If there is even a $10 \%$ increase in risk to smokers caused by ETS exposure in the workplace, their analyses consistently show that a smokefree policy is preferable to separately ventilated smoking lounges. Interestingly, at a baseline nicotine level of $4.1 \mathrm{~g} / \mathrm{m}^{3}$, the authors found no excess mortality from using a separately ventilated smoking lounge if smokers' exposure is limited to 30 minutes per day.

Most US workplaces - an estimated $87 \%$ in $1992^{4}-$ regulate smoking in some manner. Specifically, 34\% do not allow smoking anywhere inside and $25 \%$ only allow smoking in a separately ventilated smoking lounge. For employers and policy makers, a range of options exists regarding regulation of ETS in the workplace. Among the options, the least desirable is use of a designated smoking area without separate ventilation. This option provides only minimal protection to non-smokers, as previous studies have shown substantial exposure to ETS in workplaces with smoking areas without separate ven- tilation. ${ }^{5}$ The next more desirable option is the use of separately ventilated smoking lounges, which will protect non-smokers but may elevate lung cancer risk in smokers. Next, based on the current analysis, the use of separately ventilated smoking lounges with a recommended duration of 30 minutes or less per day may minimise risk to both non-smokers and smokers. Finally, the optimal alternative is a smoke-free workplace.

Beyond the clear health motives to eliminate ETS exposure, there are other factors that support smoke-free workplace policies. Smoke-free policies contribute to reduced rates of smoking initiation, decreased smoking intensity, and more successful attempts to quit . ${ }^{6}$ A smokefree policy may result in savings to employers in terms of operating and maintenance costs such as housekeeping costs, ventilating expenses, and replacement of furniture and computer equipment. ${ }^{7}$ In addition, previous studies have shown that most non-smokers ${ }^{8-10}$ and, in some cases, smokers, ${ }^{10}$ approve of smoking bans after their implementation. Population-based surveys also have shown support for banning smoking in numerous locations in the US including restaurants, indoor sporting events, and workplaces. ${ }^{11,12}$ Also in this issue of Tobacco Control, the study of McAllister ${ }^{13}$ shows strong public support of smoking bans in Australia.

Although public policies in the form of local and state laws have shown effectiveness in reducing non-smokers' exposure to ETS in the workplace, ${ }^{14,15}$ exposure remains widespread. Currently, the Occupational Safety and Health Administration (OSHA) is considering regulations that would either prohibit smoking or limit it to separately ventilated areas. ${ }^{16}$ OSHA estimates that, over the next 45 years, a workplace smoking ban would eliminate between 5500 and 32500 deaths from lung cancer and between 98000 to 578000 deaths from heart disease. The OSHA regulations would make separately ventilated smoking lounges a minimum health standard. Because of the additional cost of smoking lounges and the potential adverse health consequences, many workplaces are likely to become smoke-free in response to the OSHA regulations. OSHA should be applauded for moving forward with regulations that would result in smoke-free workplaces for most US employees. Given the recent changes in the US Congress, particularly the appointment of Representative Thomas Bliley of Virginia to head the Commerce Committee of the US House of Representatives, the OSHA activity is the only realistic chance for control of ETS at the federal level during the next few years.

Some may question the propriety of the rules proposed by OSHA based on the study of Siegel et al. Is it prudent public policy to allow separately ventilated smoking lounges when a better alternative exists for both smokers and non-smokers - namely, a total smoking ban? We believe the answer, given the current social and political climate, is "yes". The appropriate comparison, from a policy standpoint, is between the status quo and the proposals under consideration. Federal policy now does not regulate smoking in the workplace (except in certain specialised areas such as federal buildings and public transport). The rules proposed by OSHA allow two 
options, each of which is immensely better than the status quo. One of these options-a total smoking ban-is preferred for health and economic reasons. But given the policy-making process in government, which is usually incremental, one can justify the offering of options that are either ideal or slightly short of ideal, but at least significantly better than the status quo. In time, as separately ventilated smoking lounges become the accepted minimum, a total smoking ban will probably evolve as the only appropriate public policy. Of course, that process of evolution has already begun, in that many states, communities, school districts, and businesses have already banned smoking in facilities under their control.

The paper by Siegel et al also underscores the need for larger and better-designed epidemiological studies to measure the potential effects of ETS exposure on smokers. Several large case-control studies of lung cancer in the field, such as those in Connecticut, Iowa, and Missouri, may help resolve the question of ETS risk among smokers. Future pooling of well-designed epidemiological studies also may be possible. Nevertheless, it should be emphasised that health effects of ETS exposure among smokers are biologically plausible. Given the well-documented health hazards of non-smokers' exposure to ETS, and the dose-response relationships between active and passive smoking and lung cancer risk, one would expect that smokers' exposure to ETS (especially intense exposure in smoking lounges) would increase their risk of lung cancer.

In summary, the work of Siegel et al makes an important contribution to the dialogue about restriction of workplace ETS exposure. Their analysis should stimulate considerable debate among public health officials, policy makers, employers, and others involved in potential regulation of ETS. It also provides additional information with which public health advocates can educate employers on the numerous benefits of a smoke-free workplace.

School of Public Health,

ROSS C BROWNSON

Saint Louis University,

3663 Lindell Boulevard,

St Louis, Missouri 63108-3342, USA

Editor
1 US Environmental Protection Agency. Respiratory health effects of passive smoking: lung cancer and other disorders. Washington, DC: US Ensmoking: Lung cancer and other disorders. Washington, DC:
vironmental Protection Agency, 1992 . (EPA/600/6-90/006F.)

2 Burns DM. The EPA report: why the tobacco control world will never be the same. Tobacco Control $1993 ; 2: 3-4$.

3 Siegel M, Husten C, Merritt RK, Giovino GA, Eriksen MP. Effects of separately ventilated smoking lounges on the health of smokers: is this an appropriate public health policy? Tobacco Control 1995; 4: 22-9.

4 US Department of Health and Human Services. 1992 National survey of worksite health promotion activities. Washington, DC: US Department of Health and Human Services, Office of Disease Prevention and Health Promotion, 1993.

5 Repace JL. Risk management of passive smoking at work and at home. St Louis Univ Public Law Rev 1994; 14: 763-85.

6 Sorensen G. Legislation to reduce worksite exposure to environmental tobacco smoke. Tobacco Control 1994; 3 : 1-2

7 US Environmental Protection Agency. The costs and benefits of smoking restrictions. An assessment of the Smoke-Free Environment Act of 1993 (HR 3434). Washington, DC: U U Environmental Protection Agency, Office of Air and Radiation, Indoor Air Division, April 1994.

8 Peterson LR, Helgerson SC, Gibbons CM, Calhoun CR, Ciacco KH, Pitchford KC. Employee smoking behavior changes and attitudes following a restrictive policy on worksite smoking in a large company. Public Health Rep 1988; 103: 115-20.

9 Gottlieb NH, Eriksen MP, Lovato CY, Weinstein RP, Green LW. Impact of a restrictive work site smoking policy on smoking behavior, attitudes, and norms. F Occup Med 1990; 32: 16-23.

10 Borland R, Owen N, Hill D, Chapman S. Changes in acceptance of workplace smoking bans following their implementation: a prospective study. Prev Med 1990; 19: 314-22.

11 US Centers for Disease Control and Prevention. Public attitudes regarding limits on public smoking and regulation of tobacco sales and advertising limits on public smoking and regulation of tobacco sales and ad
-10 US communities, $1989 . M M W R$
1991; $40: 344-5,351-3$.

12 US Centers for Disease Control and Prevention. Attitudes toward smoking policies in eight states - United States, 1993. MMWR 1994; 43: 786-9.

13 McAllister I. Public opinion in Australia on restricting smoking in public places. Tobacco Control 1995; 4 : 30-5.

14 Pierce JP, Shanks TG, Pertschuk M, et al. Do smoking ordinances protect non-smokers from environmental tobacco smoke? Tobacco Control 1994 3: $15-20$.

15 Brownson RC, Davis JR, Jackson-Thompson J, Wilkerson JC. Environmental tobacco smoke awareness and exposure: the impact of a statewide clean indoor air law and the report of the US EPA. Tobacco Control 1995; in press.

16 Occupational Safety and Health Administration (US Department of Labor). Notice of proposed rulemaking; notice of informal public hearing. Federal Register, 1994 Apr 5; 29 CFR Parts 1910, 1915, 1926, and 1928 . 